\title{
KOMPETENSI PENDIDIK MELALUI METODE MIND MAPPING PADA TENAGA PENGAJAR DI YAYASAN ISKANDARIYAH TANGERANG SELATAN
}

\author{
${ }^{1}$ Deni Darmawan, ${ }^{2}$ Anugrah Sapto Hadi, ${ }^{3}$ Edi Junaedi, ${ }^{4}$ Ismul Bathni, \\ ${ }^{5}$ Turkamun, ${ }^{6}$ Fadhillah Aulia Rahman, ${ }^{7}$ Novia Widianti, ${ }^{8}$ Ayu Angraini \\ 1,2,3,4,5 Dosen Fakultas Ekonomi Universitas Pamulang \\ ${ }^{6,7,8}$ Mahasiswa Program Studi D-III Sekretari Universitas Pamulang \\ Email: ${ }^{1}$ dosen01723@gmail.com
}

\begin{abstract}
ABSTRAK
Tujuan dari kegiatan Pengabdian Kepada Masyarakat (PKM) yang kami laksanakan adalah sebagai bentuk implementasi salah satu Tridharma perguruan tinggi. Diharapkan dengan diadakannya pengabdian kepada masyarakat, keberadaan perguruan tinggi dapat memberikan kontribusi besar kepada pengembang dan penerapan keilmuan kepada masyarakat.

Kegiatan PKM ini terkait dengan penguasaan metode dalam proses belajar-mengajar yang harus dikuasai oleh seorang pendidik. Metode pembelajaran yang baik akan memberikan pemahaman yang utuh kepada peserta didik. Salah satu metode pembelajaran yang berbasis pada konsep peta pemikiran (Mind Mapping) merupakan cara belajar yang menggunakan konsep pembelajaran yang menyeluruh (komprehensif total- Mind Learning-TML). Metode pembelajaran Mind Mapping (Peta Pikiran) adalah salah satu metode pembelajaran yang dikembangan oleh Tony Buzan.

Metode pelaksanaan kegiatan Pengabdian Kepada Masyarakat bersifat pelatihan dan penyuluhan dengan metode ceramah, diskusi dan Tanya jawab. Setelah materi diberikan, seluruh peserta bisa berbagi mengenai permasalahan yang dihadapi dan bagaimana mengatasinya. Harapannya agar tenaga pendidik di Yayasan Iskandariyah terwujudnya pendidikan yang bermutu, ditopang dengan kemampuan tenaga pendidik yang kredibilitas dan professional, dan mempunyai kemampuan yang baik sehingga bisa membawa dampak peningkatan iklim belajar- mengajar yang bermutu.

Yayasan Pendidikan Islam Iskandariyah mempunyai satuan unit pendidikan Islam, mulai dari TK, Madrasah, MTS dan MAN. Tenaga pendidik di Yayasan Iskandirayah perlu diberikan peningkatan pengetahuan, keterampilan dan kemampuan untuk semua tenaga pendidik. Hasil kegiatan diharapkan agar pendidik Yayasan Iskandariyah mendapatkan pemahaman tentang metode pengajaran Mind Mapping, cara dan bagaimana implementasinya di dalam kelas. Dengan Kegiatan ini kompetensi pendidik melalui metode mind mapping di yayasan Iskandariyah semakin meningkatan.
\end{abstract}

Kata Kunci: Kompetensi Pendidik, Metode Mind Mapping, Tenaga Pengajar. 


\section{PENDAHULUAN}

Menurut Ahmad Munjin N. dan Lilik Nur Khalidah, (2009: 110-111) metode Mind Mapping (Peta Pikiran) adalah metode yang dikembangkan oleh Tony Buzan, kepada Brain Foundation. Peta pikiran adalah metode mencatat kreatif yang memudahkan kita mengingat banyak infomasi. Setelah selesai, catatan yang dibuat membentuk sebuah pola gagasan yang saling berkaitan, dengan topik utama di tengah, sementara subtopik dan perincian menjadi cabang-cabangnya.

Matematika, Bahasa, IPA dan agama adalah keterampilan-keterampilan otak kira, sedangkan seni, musik, pengajaran keterampilan berfikir, menggunakan otak kanan. Otak kiri bersifa memori jangka pendek dan yang biasa digunakan untuk menghafal adalah otak kiri, sehingga anak mudah lupa dengan apa yang telah dipelajari sebelumnya. Menurut Yulia Angraini (2017:9) sekolah jarang mengajak siswa untuk mengaktifkan otak kanan, padahal kreativitas berada pada sisi otak kanan. Selain itu, otak kanan juga mempunyao sifat memori jangka panjang. Artinya, memori yang disimpan diotak sebelah kanan lebih lama dari pada memori yang disimpan diotak sebelah kiri,

Menurut Syafaatul Hidayaati, Saiful Anwar, (2019:53) menjadi guru profesional harus mempunyai pengetahuan, kemampuan dan keterampilan. Seorang guru profesional harus mempunyai pengetahuan dan persediaan strategi, metode-metode pembelajaran. Seorang guru yang ingin maju dan berkembang perlu mempunyai persediaan strategi, tehnik, dan metode pembelajaran yang pasti akan selalu bermanfaat dan melaksanakan kegiatan belajar mengajar sehari-hari.

Kegiatan belajar yang optimal dapat tercapai jika guru mampu mengatur siswa dan sarana pengajaran serta mampu mengendalikan kegiatan belajar hingga muncul suasana yang menyenangkan untuk mencapai tujuan pengajaran dan merangsang siswa untuk berfikir kreatif dan pelajaran bisa disimpan dalam memori jangka panjang. Menurut Zuyyina Hasdillah Putri Maria Ulfah dan Rum Rosyid (2015:2) untuk mencapai tujuan pembelajaran yang menyenangkan dibutuhkan model pembelajaran. Salah satu tujuan penggunaan model pembelajaran adalah untuk meningkatkan kemampuan siswa selama belajar. Model pembelajaran dapat dijadikan pola pilihan, artinya para guru boleh memilih model pembelajaran yang sesuai dan efisien untuk mencapai tujuan pembelajaran.

Menurut Chusnul Nurroeni (2013 :55) Buzan mengatakan Mind Mapping adalah cara mencatat yang kreatif, efektif, dan secara harfiah akan memetakan pikiran-pikiran kita. Pembelajaran dengan model mapping tidak hanye menekankan pada kemampuan siswa untuk mengingat. Siswa juga dituntut untuk aktif mencari materi sendiri, mencari hubungan dari tiap ide, dan aktif menuangkan pikirannya dalam bentuk grafis. Menurut Sudirman (2007:75) motivasi belajar adalah factor psikis yang bersifat non-intelektual dan peranannya yang khas adalah hal penumbuhan gairah, merasa senang dan semangat untuk belajar. 
Yayasan Pendidikan Islam Iskandariyah mempunyai satuan unit pendidikan Islam, mulai dari TK, hingga SMK. Tenaga pendidik di Yayasan Iskandirayah perlu diberikan peningkatan pengetahuan, keterampilan dan karakter untuk semua tenaga pendidik. Selama ini, permasalahan yang timbul dalam Yayasan Iskandariyah adalah, Pertama, banyaknya guru yang belum menyesuaikan diri dengan perkembangan jaman. Kedua, Adanya guru yang belum menggunakan alat-alat canggih seperti komputer, laptop, infokus serta alat
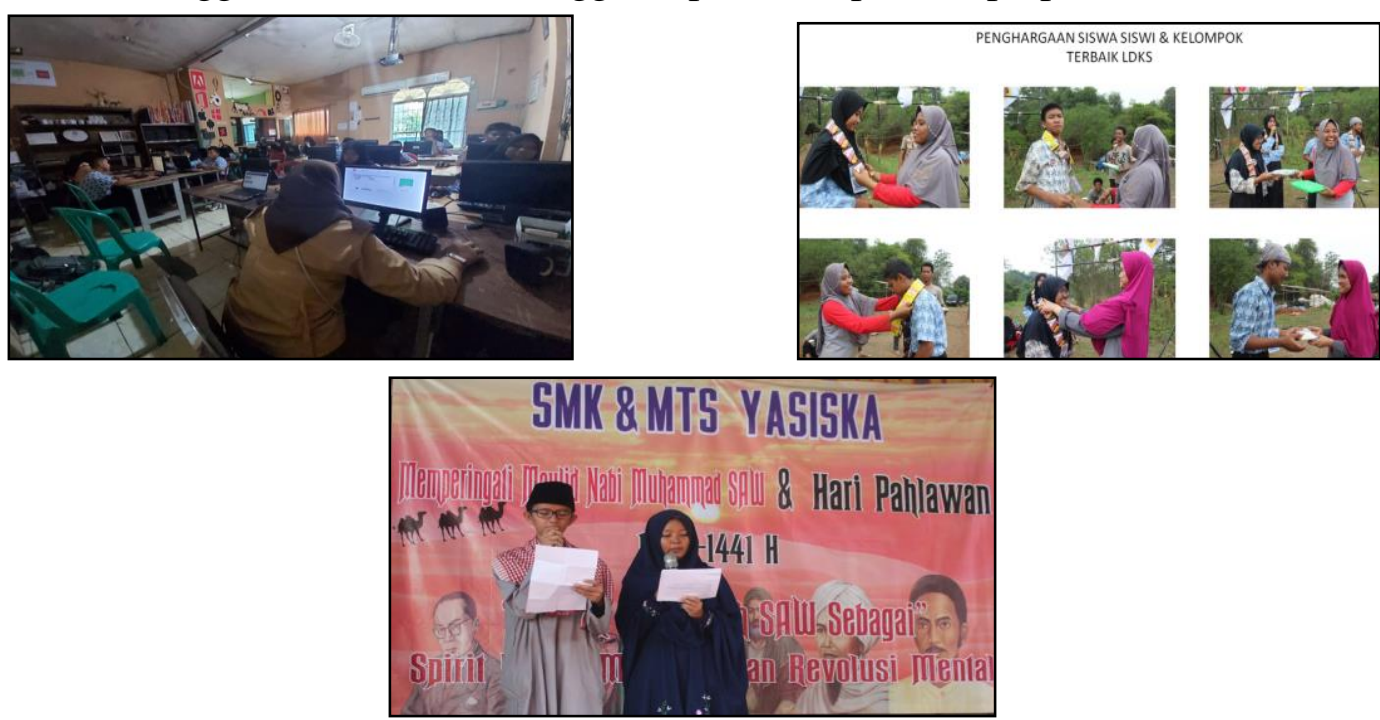

Gambar 1. Kegiatan belajar dan mengajar di Yayasan Iskandariyah

\section{METODE PELAKSANAAN KEGIATAN}

Metode dalam pelaksanaan Pengabdian Kepada Masyarakat berupa ceramah, diskusi dan tanya jawab. Materi akan disampaikan oleh dosen-dosen yang mempunyai background pendidikan. Para tenaga pendidik akan dikumpulkan pada suatu ruangan dengan tim pelaksana untuk memberikan ceramah tentang materi kegiatan. Adapun materi yang diberikan terkaait dengan pengertian metode mind mapping, cara mengajarkannya dan pentingnya metode mind mapping dalam sebuah pembelajaran. Kemudian dilanjutkan dengan metode diskusi untuk memperdalam pemahaman tenaga pendidik. Pada saat pelaksanaan kegiatan ini lebih banyak ditampilkan penjelasan-penjelasan mengenai metode mind mapping, penerapannya agar peserta dapat mudah memahaminya.
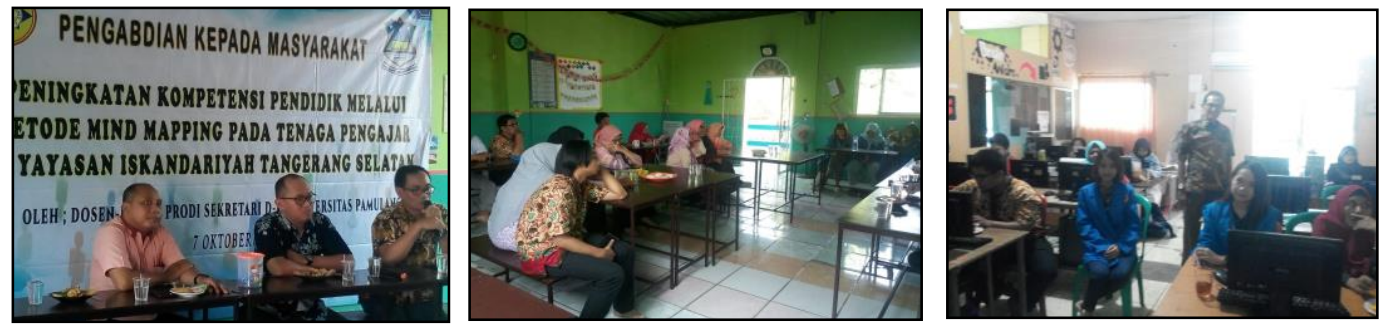

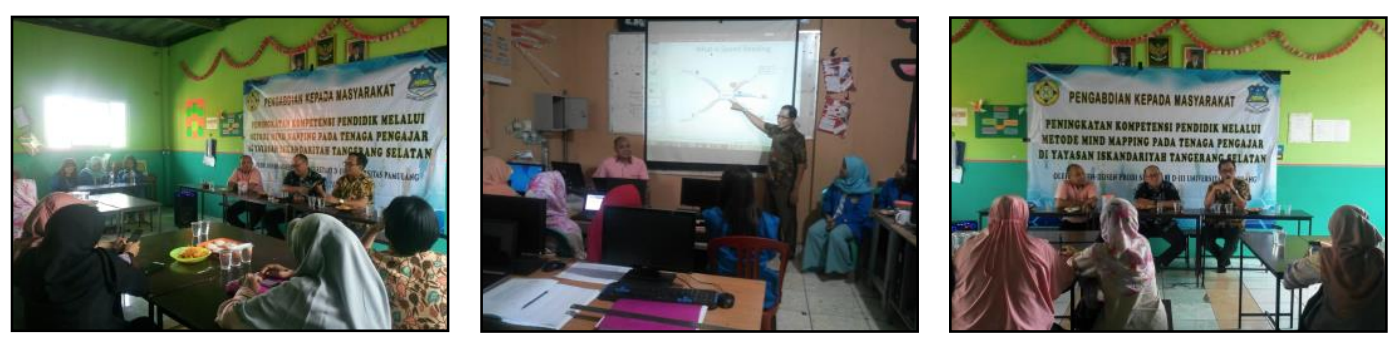

Gambar 2. Pelaksanaan PKM

Tahap pertama : Dosen pengabdi berkoordinasi dengan mahasiswa dan pengurus Yayasan Iskandariyah untuk mendapatkan izin menyelenggarakan program pengabdian kepada masyarakat sebagai salah satu tugas dosen dalam mengamalkan Tridharma perguruan tinggi

Tahap kedua : Dosen pengabdi melakukan penyuluhan dan edukasi kepada tenaga pendidik Yayasan Iskandariyah untuk meningkatkan metode pengajaran.

Tahap terakhir : Dosen pengabdi melakukan tinjauan lokasi ke tempat pengajaran dan melakukan pelatihan dan dialog kepada tenaga pendidik.

di Yayasan Pendidikan Islam Iskandariyah Jalan Aria Putra No. 44 Rt.09/10 Kelurahan Kedaung Kec. Pamulag, Kota Tangerang Selatan 15415.

Waktu pelaksanaan selama 2 hari mulai tanggal 21 sampai dengan 22 Oktober 2019.

\section{HASIL DAN PEMBAHASAN}

Metode pengajaran merupakan hal yang penting dalam proses belajar dan mengajar. Metode pengajaran seiring zaman semakin berkembang dan semakin meningkat. Penggunaan teknologi canggih dan penggunaan internet menjadi pendukung dalam metode pembelajaran. Setiap guru harus bisa menyesuaikan diri dan menerima perubahan agar bisa meningkatkan kemampuannya.

Tenaga pendidik mempunyai peran yang sangat penting dalam mengantarkan siswa berhasil dalam proses pembelajaran. Penggunaan teknologi harus bisa diimplementasikan untuk mendukung metode pembelajaran mind mapping. Oleh sebab itu, kegiatan ini mendorong tenaga pendidik untuk lebih akrab menggunakan teknologi untuk mendukung metode mind mapping untuk pembelajaran dikelas.

Yayasan Pendidikan Islam Iskandariyah mempunyai satuan unit pendidikan Islam, mulai dari TK, Madrasah, MTS dan MAN. Tenaga pendidik di Yayasan Iskandirayah setelah mengikuti PKM diharapkan semakin meningkatan pengetahuan, kemampuan dan keterampilan khususnya impelentasi metode pembelajaran mind mapping untuk semua tenaga pendidik dan siswasiswi di yayasan Iskandariyah.

Melalui kegiatan ini tenaga pendidikan mempunyai kompetensi dan menguasai metode pembelajaran mind mapping dengan didukung teknologi sehingga proses dan tujuan pembelajaran bisa tercapai. 


\section{KESIMPULAN DAN SARAN}

Kegiatan PKM ini upaya untuk mendorong peningkatan kompetensi tenaga pendidik dalam menguasai metode pembelajaran mind mapping di Yayasan Iskandariyah (Yasiska). Metode Mind Mapping bisa merangsangkan kemampuan berfikir kreatif siswa semakin meningkat. Mind Mapping merupakan salah satu konsep belajar yang paling revolusioner di dunia pendidikan. Mind Mapping sebuah tehnik pemanfaatran seluruh otak dengan menggunakan citra visual dan prasarana grafis lainnya untuk membentuk pesan.

Disarankan kepada pengurus yayasan Iskandariyah untuk selalu meningkatkan kompetensi pendidik agar tenaga pengajar Yasiska bisa meningkatkan pengajaran khususnya metode pengajaran ming mapping, agar guru bisa meransang berfikir siswa untuk kreatif dan mampu mengingat dengan baik peta pikiran dari sebuah pembelajaran.

\section{DAFTAR PUSTAKA}

Ahamad Munjin Nasih dan Likik Nur Kholidah. Metode dan Tehnik Pembelajaran Pendidikan Agama Islam. Bandung: PT. Refika Aditama. 2009

Chusnul Nurroeni. 2013. Keefektifan Penggunaan Model Mind Mapping Terhadap Aktivitas Dan Hasil Belajar IPA. Vol 2 No. 1 (2013) Jurnal Of Elementary Education. journal.unnes.ac.id

Sardiman A.M. Interaksi dan Motivasi Belajar Mengajar. Jakarta: PT. Raja Grafindo Persada ( 2007)

Sunarsi, D. (2018). Analisis Motivasi Kerja Tenaga Pendidik Sukarela Pada Pusat Kegiatan Belajar Masyarakat (PKBM) Bimasda Kota Tangerang Selatan. Kreatif: Jurnal Ilmiah Prodi Manajemen Universitas Pamulang, 6(2), 5365.

Syafaatul Hidayati, Saiful Anwar. 2019. Penerapan Metode Drill Untuk Meningkatkan Hasil Belajar Matematika Ekonomi Mahasiswa Pendidikan Ekonomi Univeritas Pamulang. Vo.4 Bo.1 (2019). Pekobis : Jurnal Pendidikan, Ekonomi dan Bisnis. Openjurnal.unpam.ac.id

Yulia Angraini,"Pengaruh model pembelajaran Mind mapping terhadap hasil belajar siswa pada materi konsep mol di SMA Negeri 1 Lubuhanhaji" (Banda Aceh:UIN AR-RANIRY,2017)

Zuyyina Hasdillah Putri, Maria Ulfah, Rum Rosyid. 2015. Penerapan Model Pembelajaran Mind Mapping Terhadap Hasil Belajar Pada Mata Pelajaran Ekonomi di SMA. Vol 4 No. 11 (2015). Jurnal Pendidikan dan Pembelajaran. Jurnal.untan.ac.id 